\title{
Trichotillomania and Related Disorders in Children and Adolescents
}

\author{
Gregory L. Hanna, MD \\ University of Michigan Medical Center
}

\begin{abstract}
Eleven chronic hair pullers, 11 subjects with obsessive-compulsive disorder (OCD), and 11 subjects with a non-OCD anxiety disorder were assessed with structured interviews and the Child Behavior Checklist (CBCL). Only 4 hair pullers (36\%) reported both rising tension and relief with hair pulling. Each group had significantly more internalizing than externalizing symptoms on the CBCL. Seven hair pullers (64\%) had a lifetime history of at least one other axis I diagnosis. The results provide further evidence that trichotillomania in referred children and adolescents is usually a chronic disorder often associated with internalizing symptoms and psychiatric comorbidity. Rising tension followed by relief with hair pulling may be an unnecessary restriction in the diagnosis of childhood trichotillomania.
\end{abstract}

KEY WORDS: Trichotillomania; Phenomenology; Comorbidity; Obsessive-Compulsive Disorder; Anxiety Disorder.

\section{Introduction}

The DSM-IV categorizes trichotillomania as an impulse control disorder not elsewhere classified, along with pathological gambling, kleptomania, pyromania, and intermittent explosive disorder. ${ }^{1}$ The majority of hair pullers report an onset in childhood or adolescence., The lifetime prevalence of the disorder in nonreferred adolescents has been estimated to be $1 \%{ }^{4}$ Somewhat higher rates have been obtained in studies of college freshmen. ${ }^{5,6}$

Trichotillomania has been considered previously as a habit disorder analogous to nail biting and as a manifestation of intrapsychic conflict. ${ }^{7,8,9}$ It has been suggested more recently that trichotillomania is

Received March 6, 1996; For Revision June 24, 1996; Accepted July 28, 1996.

Address correspondence to Gregory L. Hanna, M.D., Department of Psychiatry, Child and Adolescent Psychiatric Hospital, University of Michigan Medical Center, 1500 East Medical Center Drive, Ann Arbor, MI 48109-0390.

The author thanks Neil M. Kalter, Ph.D. (Departments of Psychology and Psychiatry, University of Michigan) for statistical consultation. 
related to the mood and anxiety disorders, because patients with the disorder have increased lifetime prevalence rates of mood and anxiety disorders and often have an initial response to serotonergic antidepressants or lithium..$^{2,10,11,12}$ Some reports have commented, in particular, on a possible relationship between trichotillomania and obsessive-compulsive disorder (OCD), suggesting that they belong to a spectrum of disorders having in common pathologic compulsions of excessive grooming. ${ }^{13,14,15}$ Others have found, however, significant differences between trichotillomania and OCD in gender distribution, age at onset, phenomenology, comorbidity, neurobiology, and treatment response. ${ }^{2,5,16,17,18,19,20,21,22,23}$ A possible relationship between trichotillomania and the tic disorders has also been suggested by epidemiological and clinical data. ${ }^{4,18}$

The DSM-IV characterizes trichotillomania as "recurrent pulling out of one's own hair for pleasure, gratification, or release of tension that results in noticeable hair loss" (p. 609). Consistent with its classification as an impulse control disorder, DSM-IV criteria further require an "increasing sense of tension immediately before pulling out the hair" followed by "pleasure, gratification, or relief when pulling out the hair" (p. 621). However, a study of adult hair pullers found that $17 \%$ failed to describe both rising tension before hair pulling and relief during or after pulling. ${ }^{2}$ Studies of hair pulling in children and adolescents determined that 27 to $90 \%$ failed to endorse one or both of these phenomena, so that these criteria appear to be even more problematic for younger hair pullers. ${ }^{18,19}$ In short, there are unresolved controversies about the appropriate diagnostic criteria and classification of trichotillomania.

There is limited information about the demographics, phenomenology, and psychiatric comorbidity of childhood trichotillomania. ${ }^{15,18,19}$ Because trichotillomania is classified as an impulse control disorder, the relative severity of internalizing and externalizing symptoms associated with the disorder requires further examination. Although parallels have been drawn between trichotillomania and OCD, few studies have directly and systematically compared the two disorders. ${ }^{17,18,20}$ The relationship of trichotillomania to anxiety disorders other than OCD has received even less empirical study. Hence, this study examined the psychiatric symptoms associated with hair pulling and the relationship of trichotillomania to OCD and other anxiety disorders by comparing the demographic and clinical features of children and adolescents with either trichotillomania, OCD, or a nonOCD anxiety disorder. It was hypothesized that hair pulling would be 
associated with more internalizing than externalizing symptoms, but that tension changes would not necessarily be associated with hair pulling leading to noticeable hair loss.

\section{Method}

\section{Subjects}

The sample consisted of 11 subjects with trichotillomania who were matched by age and sex with 11 subjects with OCD and 11 subjects with a non-OCD anxiety disorder. Each group contained 7 girls and 4 boys who ranged in age from 7 to 17 years. The average age (mean \pm SD) was $12.2 \pm 2.7$ years for the trichotillomania group, $11.9 \pm 2.6$ years for the OCD group, and $12.4 \pm$ 3.6 years for the non-OCD anxiety disorder group. All subjects were referred to a specialty outpatient clinic during a 36 month period for a chief complaint of hair pulling, rituals, or anxiety. They were grouped according to the problem for which they were initially referred for evaluation or treatment.

The trichotillomania subjects were required to have visible hair loss that was acknowledged by the child to result from hair pulling or was observed by an adult after hair pulling. They were included in the trichotillomania group even if they failed to describe mounting tension before hair pulling and gratification or relief while hair pulling as required by DSM-IV criteria. ${ }^{24}$ The comparison subjects met DSM-III-R criteria for OCD or another anxiety disorder and were required to have no history of hair pulling or noticeable hair loss. The diagnoses of the subjects in the non-OCD anxiety disorder group were separation anxiety disorder (5), panic disorder (2), social phobia (2), overanxious disorder (1), and simple phobia (1).

Subjects referred primarily for hair pulling who met DSM-III-R criteria for OCD were excluded to minimize the overlap between the trichotillomania and OCD groups. This resulted in the exclusion of two potential subjects. Subjects referred primarily for hair pulling who met DSM-III-R criteria for a non-OCD anxiety disorder were included in the trichotillomania group. Subjects referred primarily for OCD who met DSM-III-R criteria for another anxiety disorder were included in the OCD group. Two subjects were excluded because they could not cooperate with study procedures. Other exclusion criteria were mental retardation, pervasive developmental disorder, organic mental disorder, or psychosis. None of the subjects received medication or other forms of treatment for at least 2 weeks before the evaluation.

\section{Clinical Assessment}

Before the first appointment, each child completed the Children's Depression Inventory (CDI ${ }^{25}$ and a parent of each child completed the Yale Children's Inventory ${ }^{26}$ and the Child Behavior Checklist (CBCL). ${ }^{27}$ Social status was determined for each family with the two-factor index of social position. ${ }^{28}$ At the first appointment, each child and his/her parents received a standard clinical psychiatric assessment which included a review of past medical, psy- 
chiatric, and school records; an interview of the child and parents together; an interview of the child alone; and an interview of the parents.

Each child and his/her parent were interviewed with the Diagnostic Interview for Children and Adolescents (DICA) including the tic section of the parent interview. ${ }^{19,29}$ All subjects in the trichotillomania group were assessed in a systematic manner about onset and life events; current and past anatomical sites; awareness, affective concomitants, and context of hair pulling; presence or absence of concurrent mounting tension or relief; routines or rituals involving plucked hair, including trichophagy; and treatment history. The obsession and compulsion checklists of the child and adolescent Yale-Brown Obsessive Compulsive Scale (CY-BOCS) (0,31 $^{30}$ was used to ask specific and detailed questions about the onset and course of current and past obsessive-compulsive symptoms. All interviews were performed by a board-certified child and adolescent psychiatrist. All axis I disorders, with the exception of trichotillomania, were diagnosed according to DSM-III-R criteria. All diagnoses were made before scoring the CBCL.

\section{Data Analysis}

Student's $t$ tests and analysis of variance were used to compare differences in the means between groups. Post-hoc comparisons were made with the Dunn / Bonferroni procedure. ${ }^{32}$ Chi-square tests were used to examine categorical data. In the analysis of the CBCL data, $T$ scores were used to permit comparisons between both sexes and different ages and to allow comparison of the sample with previously described samples. ${ }^{27}$ The CBCL syndrome (problem) $T$ scores for the three groups were compared by a multivariate analysis of variance. This analysis was also performed on seven variables derived from the difference between the $T$ score for each problem scale and that of the adjacent scale so that the results could be compared with those of King and colleagues. ${ }^{18}$ Data are reported as mean \pm standard deviation. All probability values reported are two-tailed with significance stipulated as $p \leq .05$.

\section{Results}

\section{Clinical Characteristics of Hair Pulling}

The clinical characteristics of hair pulling in 11 children and adolescents are summarized in Table 1. Almost half of the subjects (45\%) described a life event (e.g., start of the school year, move to the United States, automobile accident ) associated with the onset of their hair pulling. Six subjects (54\%) had pulled hair from two or more sites. Three subjects (27\%) had pulled scalp hair exclusively, and two subjects (18\%) had pulled eyelashes exclusively. Almost half (45\%) of 
Table 1

Clinical Characteristics of Hair Pulling in 11 Children and Adolescents with Trichotillomania

\begin{tabular}{llr}
\hline & No. & $\%$ \\
\cline { 2 - 3 } & 5 & 45 \\
Events associated with onset of hair pulling & 9 & 82 \\
Pulling from scalp hair & 8 & 73 \\
Pulling from eyelashes & 4 & 36 \\
Pulling from eyebrows & 1 & 9 \\
Pulling from arm hair & 5 & 45 \\
Routine or ritual with pulled hair & 5 & 45 \\
Pulling at bedtime & 4 & 36 \\
Pulling during another activity at home & 2 & 18 \\
Pulling when angry & 2 & 18 \\
Pulling at no particular time & 8 & 73 \\
Awareness of hair pulling & 5 & 45 \\
Increasing sense of tension before pulling or & & \\
when attempting to resist the behavior & 4 & 36 \\
Pleasure, relief, or gratification when pulling & & \\
\hline
\end{tabular}

the subjects described having a routine or ritual involving their plucked hair (e.g., inspecting, counting, saving, hiding, smelling, sucking, or eating pulled hair).

The majority of the subjects ( $82 \%)$ noted that they were more likely to pull hair at home than at school. Those with more awareness of their hair pulling described pulling during specific situations when they were tired, alone, bored, or distracted (e.g., falling asleep at night, reading, doing homework, watching television). Three subjects (27\%) denied having any awareness of their hair pulling. Although all subjects had cosmetically apparent hair loss, only 4 subjects (36\%) described having both an increasing sense of tension immediately before hair pulling or when attempting to resist the behavior and pleasure, gratification, or relief when hair pulling.

The subjects who met all DSM-IV criteria for trichotillomania had a significantly higher socioeconomic status than did those who denied mounting tension before hair pulling or relief while hair pulling (1.4 \pm 0.55 versus $3.2 \pm 1.6, \mathrm{t}=2.34$, d.f. $=9, \mathrm{p}=0.04$ ). However, that difference failed to reach statistical significance when the raw scores were compared $(17.0 \pm 4.8$ versus $35.2 \pm 18.7, t=2.10$, d.f. $=9, p$ $=0.06$ ). There were no other significant demographic or clinical differences between those two groups. 


\section{Group Comparisons}

The demographic characteristics and rating scale scores of the three groups are summarized in Table 2. The mean age at onset for hair pulling was 8.5 years with a range of 2 to 13.5 years. The mean duration of hair pulling was 3.7 years with a range of 1 to 7.6 years. There were no significant differences between the three groups in socioeconomic status, age at assessment, age at onset, duration of illness, or CDI scores. Boys were significantly older than girls in the full sample $(13.6+2.9$ versus $11.3+2.6$ years, unpaired $t=2.34$, d.f. $=$ $31, p=0.03$ ). This age difference did not reach significance within the trichotillomania group. There were no significant gender differences in socioeconomic status, age at onset, duration of illness, CDI scores, or CBCL $T$ scores.

With the CBCL, the Internalizing $T$ scores were significantly higher than the Externalizing $T$ scores in the full sample (paired $t=8.52$, d.f. $=32, p=0.0001$ ). Furthermore, the Internalizing $T$ scores were significantly higher than the Externalizing $T$ scores within the trichotillomania group (paired $t=4.78$, d.f. $=10, p=0.0007$ ), within the OCD group (paired $t=6.14$, d.f. $=10, p=0.0001$ ), and within the non-OCD anxiety disorder group (paired $t=4.21$, d.f. $=10, p=$ 0.002 ). However, there were no significant group differences in the Total Problem, Internalizing, Externalizing, or competence $T$ scores.

A few significant differences in the CBCL syndrome scales differentiated between the three groups. The mean Thought Problems $T$ score was increased by more than two standard deviations in the OCD group and by more than one standard deviation in the trichotillomania group. The Thought Problems scale contains items rating obsessions and compulsions. There was a significant group effect for the Thought Problems $T$ scores $(F[2,30]=18.72, \mathrm{p}=0.0001$ ). The Thought Problems $T$ scores were significantly higher in the OCD group than in both the trichotillomania group $(p=0.014)$ and the non-OCD anxiety disorder group $(p=0.0001)$. Furthermore, the Thought Problems $T$ scores were significantly higher in the trichotillomania group than in the non-OCD anxiety disorder group $(\mathrm{p}=$ 0.002). With the MANOVA of the CBCL syndrome scale $T$ scores, there was a significant group effect on the CBCL profile $(\mathrm{F}[7,24]=$ $16.63, \mathrm{p}=0.0001$, Wilks' $\lambda=0.171$ ). With the MANOVA of the variables derived from the CBCL syndrome scale $T$ scores, there was also a significant group effect on the CBCL profile $(F[6,25]=13.52, p=$ 0.0001 , Wilks' $\lambda=0.236$ ). 


\section{Table 2}

Demographic and Rating Scale Characteristics of Children and Adolescents with Trichotillomania, Obsessive-Compulsive Disorder, or Another Anxiety Disorder

\begin{tabular}{|c|c|c|c|}
\hline & $\begin{array}{c}\text { Trichotillomania } \\
(N=11) \\
(\text { Mean }+S D)\end{array}$ & $\begin{array}{c}O C D^{\mathrm{a}} \\
(N=11) \\
(\text { Mean }+S D)\end{array}$ & $\begin{array}{c}\text { Anxiety Disorder } \\
(N=11) \\
(\text { Mean }+S D)\end{array}$ \\
\hline Socioeconomic status & $2.4+$ & $2.2+1.2$ & $2.7+$ \\
\hline $\begin{array}{l}\text { Age at presentation, } \\
\text { years }\end{array}$ & $12.2+$ & $11.9+2.6$ & $12.4+3.6$ \\
\hline $\begin{array}{l}\text { Age at onset of illness, } \\
\text { years }\end{array}$ & $8.5+3.3$ & $9.0+3.2$ & $9.3+3.9$ \\
\hline Duration of illness, years & $3.7+2.2$ & $3.0+$ & $3.0+$ \\
\hline CDI s & $11.9+12.1$ & $11.7+7.8$ & $11.8+8.4$ \\
\hline $\begin{array}{l}\text { CBCL Total Problem } T \\
\text { score }^{\text {c }}\end{array}$ & $61.1+12.6$ & $66.9+10.6$ & $60.8+10.2$ \\
\hline $\begin{array}{l}\text { CBCL Internalizing } T \\
\text { score }\end{array}$ & $64.5+11.3$ & $71.2+10.6$ & $67.1+9.6$ \\
\hline $\begin{array}{l}\text { CBCL Externalizing } T \\
\text { score }\end{array}$ & $52.5+13.4$ & $54.1+8.7$ & $51.1+11.3$ \\
\hline CBCL Withdrawn $T$ score & $56.2+18.5$ & $65.4+11.7$ & $62.3+7.2$ \\
\hline CBCL Somatic $T$ score & $59.4+8.6$ & $65.4+6.7$ & $64.8+9.8$ \\
\hline $\begin{array}{l}\text { CBCL Anxious / De- } \\
\text { pressed } T \text { score }\end{array}$ & $67.1+12.8$ & $75.2+14.8$ & $66.3+8.8$ \\
\hline $\begin{array}{l}\text { CBCL Social Problems } T \\
\text { score }\end{array}$ & $62.4+8.9$ & $59.8+12.0$ & $58.4+8.6$ \\
\hline $\begin{array}{l}\text { CBCL Thought Problems } \\
T \text { score }\end{array}$ & $67.5+8.0$ & $76.9+9.4$ & $55.1+7.6^{\mathrm{d}}$ \\
\hline $\begin{array}{l}\text { CBCL Attention Prob- } \\
\text { lems } T \text { score }\end{array}$ & $63.1+11.0$ & $66.8+14.2$ & $57.3+6.3$ \\
\hline $\begin{array}{l}\text { CBCL Delinquent Behav- } \\
\text { ior } T \text { score }\end{array}$ & $55.0+7.7$ & $53.4+5.9$ & $53.2+4.8$ \\
\hline $\begin{array}{l}\text { CBCL Aggressive Behav- } \\
\text { ior } T \text { score }\end{array}$ & $57.2+8.7$ & $56.8+7.2$ & $56.5+8.3$ \\
\hline $\begin{array}{l}\text { CBCL Total Competence } \\
T \text { score }\end{array}$ & $42.2+11.9$ & $40.4+11.4$ & $43.0+9.7$ \\
\hline CBCL Activities $T$ & $47.9+$ & $45.0+8.0$ & $46.6+$ \\
\hline CBCL Social $T$ score & $40.0+9.9$ & $37.0+16.1$ & $43.8+6.9$ \\
\hline CBCL School $T$ score & $39.1+10.2$ & $43.1+10.0$ & $40.4+10.7$ \\
\hline
\end{tabular}

${ }^{\mathrm{a}} \mathrm{OCD}=$ obsessive-compulsive disorder.

${ }^{\mathrm{b}} \mathrm{CDI}=$ Children's Depression Inventory.

${ }^{\circ} \mathrm{CBCL}=$ Child Behavior Checklist.

${ }^{\mathrm{d}} \mathrm{F}[2,30]=18.72, \mathrm{p}=0.0001$. 
The lifetime axis I psychiatric diagnoses associated with trichotillomania, OCD, and the non-OCD anxiety disorders are summarized in Table 3. Most subjects (73\%) in the full sample had a history of comorbid psychopathology. Seven hair pullers (64\%) had a lifetime history of at least one other axis I diagnosis. Five hair pullers $(45 \%)$ had a lifetime diagnosis of at least one mood or non-OCD anxiety disorder.

Of the individual disorders, only the lifetime prevalence of major depression was significantly different between the three groups, with

\section{Table 3}

Associated Lifetime Axis I Psychopathology in Children and Adolescents with Trichotillomania, Obsessive-Compulsive Disorder, or Another Anxiety Disorder

\begin{tabular}{|c|c|c|c|}
\hline & \multicolumn{3}{|c|}{ No. (\%) of Patients ${ }^{\mathrm{a}}$} \\
\hline & $\begin{array}{l}\text { Trichotillomania } \\
\quad(N=11)\end{array}$ & $\begin{array}{c}O C D^{\mathrm{b}} \\
(N=11)\end{array}$ & $\begin{array}{c}\text { Anxiety Disorder } \\
(N=11)\end{array}$ \\
\hline Mood disorder & $4(36)$ & $7(64)$ & $2(18)$ \\
\hline Major depression & $0 \quad(0)$ & $3(27)$ & $0(0)^{c}$ \\
\hline Dysthymia & $4(36)$ & $2(18)$ & $0 \quad(0)$ \\
\hline $\begin{array}{l}\text { Depressive Disorder, } \\
\text { NOS }^{d}\end{array}$ & $0 \quad(0)$ & $2(18)$ & $2(18)$ \\
\hline $\begin{array}{l}\text { Anxiety disorder other } \\
\text { than OCD }\end{array}$ & $4(36)$ & $2(18)$ & $6(54)$ \\
\hline $\begin{array}{l}\text { Separation Anxiety } \\
\text { Disorder }\end{array}$ & 1 (9) & $0 \quad(0)$ & $3(27)$ \\
\hline Overanxious Disorder & $3(27)$ & $2(18)$ & $2(18)$ \\
\hline Simple Phobia & $0(0)$ & 1 (9) & $2(18)$ \\
\hline $\begin{array}{l}\text { Disruptive behavior dis- } \\
\text { order }\end{array}$ & $3(27)$ & $4(36)$ & $3(27)$ \\
\hline $\begin{array}{l}\text { Attention-Deficit } \\
\text { Hyperactivity Disorder }\end{array}$ & $2(18)$ & $3(27)$ & $0 \quad(0)$ \\
\hline $\begin{array}{l}\text { Oppositional-Defiant } \\
\text { Disorder }\end{array}$ & 1 (9) & 1 (9) & $3(27)$ \\
\hline Chronic Tic Disorder & $1(9)$ & $0 \quad(0)$ & $1(9)$ \\
\hline Enuresis & $2(18)$ & $0 \quad(0)$ & 1 (9) \\
\hline $\begin{array}{l}\text { Habits (e.g, nailbiting, } \\
\text { cuticle, skin, or scab } \\
\text { picking) }\end{array}$ & $4(36)$ & $5(45)$ & $4(36)$ \\
\hline
\end{tabular}

Multiple diagnoses were given to some patients.

${ }^{\mathrm{b}} \mathrm{OCD}=$ obsessive-compulsive disorder.

${ }^{\mathrm{c}} \chi^{2}=6.6$, d.f. $=2, p=0.037$.

${ }^{\mathrm{d}} \mathrm{NOS}=$ not otherwise specified. 
all diagnoses occurring within the $\operatorname{OCD}$ group $\left(\chi^{2}=6.6\right.$, d.f. $=2, p=$ $0.037)$. Five hair pullers (45\%) had a history of obsessive-compulsive symptoms not involving hair that failed to meet diagnostic criteria for OCD. Four subjects (36\%) in the non-OCD anxiety disorder group also had a history of subclinical obsessive-compulsive symptoms. The difference between those two groups in the rate of obsessive-compulsive symptoms was not significant.

Three hair pullers had been treated in the past with medication (fluoxetine, 1; stimulants, 2). Four OCD subjects had been treated previously with medication (imipramine, 1 ; fluoxetine, 1 ; methylphenidate, 1 ; trazodone and hydroxyzine hydrochloride, 1 ). Two subjects in the non-OCD anxiety disorder group had been treated previously with medication (alprazolam, 1; imipramine, sertraline, paroxetine, alprazolam, and lorazepam, 1). None of these medications had been associated with substantial clinical improvement. Nine hair pullers, 4 OCD subjects, and 6 subjects with a non-OCD anxiety disorder had been treated in the past with individual and/or family therapy.

\section{Discussion}

Most chronic hair pullers in this study expressed awareness of their hair pulling. Only about half of them, however, endorsed both rising tension and relief with hair pulling. A majority had a lifetime history of at least one other axis I diagnosis. Trichotillomania was associated with more internalizing than externalizing symptoms on the CBCL. As might be expected, OCD and the non-OCD anxiety disorders were also associated with a preponderance of CBCL internalizing symptoms. The CBCL Thought Problems scale differentiated between the three groups. Some subjects with either trichotillomania or a nonOCD anxiety disorder reported a history of obsessive-compulsive symptoms.

Most of the demographic and clinical features of the hair pullers in this study are similar to those reported in recent studies of children and adolescents with trichotillomania. ${ }^{3,15,18,19}$ However, the small sample size limited the power to detect differences between hair pullers who met full criteria for trichotillomania and those who did not and to detect differences between the three diagnostic groups. The referral patterns of a tertiary medical center influence the severity, chronicity, and comorbidity of a clinical series so that the findings on 
trichotillomania in the present study may not be generalizable to the disorder as it exists in the general population. ${ }^{33}$

The majority of the hair pullers in this series were female. This is consistent with the strong preponderance of females found in most clinical studies of children, adolescents, and adults with trichotillomania. ${ }^{15,18,19,34,35,36}$ However, a more even gender distribution was noted in children than in adults in a survey of hair-pulling. ${ }^{3}$ In addition, males slightly outnumbered females in an epidemiological study of trichotillomania in adolescents. ${ }^{4}$ The differences in the sex ratios between referred and nonreferred samples may reflect gender differences in age of onset, severity, comorbidity, or treatment-seeking behavior.

The mean age at onset of hair pulling in this study is consistent with recent studies of hair pulling in children and adolescents., ${ }^{3,418,19}$ Only one subject in this series began pulling hair before age six, and the behavior persisted for over five years. Thus, this sample is not representative of hair pulling in preschool children who according to some authors may have a milder form of the disorder with a shorter course. ${ }^{7,37,38}$

Eight hair pullers (73\%) in this study reported being aware at least occasionally of their hair pulling as it occurred. Only four hair pullers $(36 \%)$ acknowledged having both an increasing sense of tension before hair pulling and a relief of tension with hair pulling. Thus, $64 \%$ of the subjects failed to meet the DSM-IV criteria for trichotillomania. The possible relationship between socioeconomic status and tension changes associated with hair pulling requires further examination in a larger sample of hair pullers.

In a slightly younger sample of hair pullers than the present sample, only $10 \%$ reported both rising tension and relief. ${ }^{19}$ In a slightly older sample than the present sample, the $27 \%$ who failed to endorse one or both of these phenomena were disproportionately in the younger half of the group. ${ }^{18}$ In 60 adult chronic hair pullers, $17 \%$ failed to describe both phenomena. ${ }^{2}$ Thus, as has been suggested previously, the awareness of internal states and the ability to report rising tension and relief may be related to cognitive development and/or to neurobiological changes associated with chronic hair pulling. ${ }^{18,19}$ Furthermore, the tension requirement in the DSM-IV may be irrelevant to the diagnosis of trichotillomania in children and adolescents. Studies with larger samples of both types of hair pullers are necessary to adequately test the validity of this requirement in the diagnosis of childhood trichotillomania. 
The three groups were similar in their demographic measures and in most of their rating scale measures. The CBCL ratings demonstrated that the full sample had significantly more internalizing than externalizing symptoms. Furthermore, that difference was statistically significant within each group. A relative increase in CBCL internalizing symptoms was noted in a previous study of young hair pullers. ${ }^{19}$ The low frequency of externalizing symptoms in the CBCL ratings of the hair pullers in the present study is consistent with studies indicating that trichotillomania is not associated with generalized problems of impulse control. ${ }^{23,39}$ The denial by over half of the subjects of rising tension before hair pulling also suggests that this disorder may not be appropriately classified as an impulse control disorder.

The lifetime prevalence of comorbid axis I diagnoses in the hair pullers was $64 \%$, a figure in-between the rates found in previous studies of childhood trichotillomania. ${ }^{18,19}$ The broad range of associated psychopathology in the hair pullers indicates that trichotillomania is heterogeneous in its comorbidity as well as in its severity and chronicity. In addition to the preponderance of internalizing symptoms in the CBCL ratings, almost half of the trichotillomania patients had a history of at least one mood or non-OCD anxiety disorder. The lifetime prevalence of major depression was higher in the OCD group than in the other two groups. This is consistent with a trend noted in a study comparing adults with either trichotillomania or OCD for an increased rate of major depression in the OCD subjects. ${ }^{17}$ However, the hair pullers with a history of dysthymia are at risk for future episodes of major depression. ${ }^{40}$ Thus, the difference between the three groups in lifetime prevalence of major depression may not be robust over time. Taken together, the pattern of comorbid symptoms and categorical diagnoses gives some support for the concept of trichotillomania as an internalizing disorder or "affective spectrum disorder"."

About half of the hair pullers and a third of the non-OCD anxiety disorder subjects had a history of obsessive-compulsive symptoms that failed to meet diagnostic criteria for OCD. No obsessions or compulsions were identified in a previous study of childhood trichotillomania. ${ }^{19}$ However, other clinical and epidemiological studies have diagnosed OCD in some children and adolescents with trichotillomania. ${ }^{4,18}$ The CBCL Thought Problems scale discriminated between the three groups primarily because of the obsession and compulsion items on that scale. The significant differences between the groups on 
the CBCL Thought Problems scale and the significant group effect in the multivariate analysis of the CBCL syndrome scale profile replicate the findings of King and colleagues. ${ }^{18}$ One interpretation of the limited data on childhood trichotillomania is that a form of the disorder is related to OCD and perhaps to generalized anxiety disorder and the chronic tic disorders. ${ }^{4}$ Comparative studies with larger samples are necessary to clarify the relationship of trichotillomania to OCD and other psychiatric disorders.

\section{Summary}

The study provides further evidence that trichotillomania in children and adolescents referred for psychiatric services is usually a chronic disorder that is often associated with other psychiatric disorders. Hair pulling was associated with a preponderance of internalizing symptoms on the CBCL, as were OCD and the other anxiety disorders, suggesting that trichotillomania may not be appropriately classified as an impulse control disorder. Obsessive-compulsive symptoms were reported by subjects with either trichotillomania or a nonOCD anxiety disorder. However, the CBCL Thought Problems scale differentiated between the three groups. The requirement of rising tension followed by relief or gratification with hair pulling may be an unnecessary restriction in the diagnosis of childhood trichotillomania. Further epidemiological and family studies of trichotillomania are necessary to refine the diagnostic criteria for the disorder and to determine its appropriate classification.

\section{References}

1. American Psychiatric Association. Diagnostic and Statistical Manual of Mental Disorders, Fourth Edition. Washington, D. C.: American Psychiatric Association, 1994.

2. Christenson GA, Mackenzie TA, Mitchell JE: Characteristics of 60 adult hair pullers. Am J Psychiatry 148, 365-370, 1991.

3. Cohen LJ, Stein DJ, Simeon D, Spadaccini E, Rosen J, Aronowitz B, Hollander E: Clinical profile, comorbidity, and treatment history in 123 hair pullers: A survey study. J Clin Psychiatry 56, 319-326, 1995.

4. King RA, Zohar AH, Ratzoni G, Binder M, Kron S, Dycian A, Cohen DJ, Pauls DL, Apter A: An epidemiological study of trichotillomania in Israeli adolescents. J Am Acad Child Adolesc Psychiatry 34, 1212-1215, 1995.

5. Christenson GA, Pyle RL, Mitchell JE: Estimated lifetime prevalence of trichotillomania in college students. $J$ Clin Psychiatry 52, 415-417, 1991. 
6. Rothbaum BO, Shaw L, Morris R, Ninan PT: Prevalence of trichotillomania in a college freshman population (letter). J Clin Psychiatry 54, 72, 1993.

7. Oranje AP, Peereboom-Wynia JD, DeRaeymacker DM: Trichotillomania in childhood. J Am Acad Dematology 15, 614-619, 1986.

8. Delgado RA, Mannino FV: Some observations on trichotillomania in children. $J A m$ Acad Child Psychiatry 8, 229-246, 1969.

9. Greenberg HR, Sarner CA: Trichotillomania: Symptom and syndrome. Arch Gen Psychiatry 12, 482-489, 1965.

10. Christenson GA, Popkin MK, Mackenzie TB, Realmuto GM: Lithium treatment of chronic hair pulling. $J$ Clin Psychiatry 52, 116-120, 1991.

11. McElroy SL, Hudson JI, Pope HG, Keck PE, Aizley HG: The DSM-III-R impulse control disorder not elsewhere classified: Clinical characteristics and relationship to other psychiatric disorders. Am J Psychiatry 149, 318-327, 1992.

12. Swedo SE, Leonard HL, Rapoport JL, Lenane MC, Goldberger EL, Cheslow DL: A double blind comparison of clomipramine and desipramine in the treatment of trichotillomania (hair pulling). $N$ Engl J Med 321, 497-501, 1989.

13. Jenicke MA: Obsessive-compulsive disorder and related disorders: A hidden epidemic. $N$ Engl $J$ Med 321:539-541, 1989.

14. McElroy SL, Hudson JI, Phillips KA, Keck PE, Pope HG: Clinical and theoretical implications of a possible link between obsessive-compulsive and impulse control disorders. Depression 1, 121-132, 1993.

15. Swedo SE, Leonard HL: Trichotillomania: An obsessive compulsive disorder? Psychiatric Clinics $N$ Am 15:777-790, 1992.

16. Christenson GA, Mackenzie TA, Mitchell JE, Callies A: A placebo controlled double blind crossover study of fluoxetine in trichotillomania. Am J Psychiatry 148, 15661571, 1991.

17. Himle JA, Bordnick PS, Thyer BA: A comparison of trichotillomania and obsessivecompulsive disorder. I Psychopathology Behav Assess 17:251-260, 1995.

18. King RA, Scahill L, Vitulano LA, Schwab-Stone M, Tercyak KP Jr, Riddle MA; Childhood trichotillomania: Clinical phenomenology, comorbidity, and family genetics. J Am Acad Child Adolesc Psychiatry 34, 1451-1459, 1995.

19. Reeve EA, Bernstein GA, Christenson GA: Clinical characteristics and psychiatric comorbidity in children with trichotillomania. J Am Acad Child Adolesc Psychiatry 31:132-138, 1992.

20. Stanley MA, Swann AC, Bowers TC, Davis ML, Taylor DJ: A comparison of clinical features in trichotillomania and obsessive-compulsive disorder. Behav Res Ther 30 , 39-44, 1992.

21. Swedo SE, Rapoport JL, Leonard HL, Schapiro MB, Rapoport SI, Grady CL: Regional cerebral glucose metabolism of women with trichotillomania. Arch Gen Psy. chiatry 48, 828-833, 1991.

22. Streichenwein SM, Thornby JI: A long-term, double-blind, placebo-controlled crossover trial of the efficacy of fluoxetine for trichotillomania. Am $J$ Psychiatry 152, 1192-1196, 1995.

23. Winchel RM, Jones JS, Stanley B, Molcho A, Stanley M: Clinical characteristics of trichotillomania and its response to fluoxetine. $J$ Clin Psychiatry 53, 304-308, 1992.

24. American Psychiatric Association. Diagnostic and Statistical Manual of Mental Disorders, Third Edition, Revised. Washington, D. C.: American Psychiatric Association, 1987.

25. Kovacs M: Children's Depression Inventory. North Tonawands, NY: Multi-Health Systems, Inc., 1992.

26. Shaywitz SE, Shaywitz BA, Schnell C, Towle VR: Concurrent and predictive validity of the Yale Children's Inventory: An instrument to assess children with attentional deficits and learning disabilities. Pediatrics 81, 562-571, 1988. 
27. Achenbach TM: Manual for the Child Behavior Checklist/4-18 and 1991 Profile. Burlington, VT: University of Vermont Department of Psychiatry, 1991.

28. Hollingshead AB: Two-Factor Index of Social Position. New Haven, CT: Yale University Department of Sociology, 1965.

29. Welner Z, Reich W, Herjanic B, Jung K, Amado H: Reliability, validity and child agreement studies of the Diagnostic Interview for Children and Adolescents (DICA). J Am Acad Child Adolesc Psychiatry 26, 649-653, 1987.

30. Goodman WK, Price LH, Rasmussen SA, Mazure C, Fleischmann RL, Hill CL, Heninger GR, Charney DS: The Yale-Brown Obsessive Compulsive Scale I. Development, use, and reliability. Arch Gen Psychiatry 46, 1006-1011, 1989.

31. Goodman WK, Price LH, Rasmussen SA, Mazure C, Delgado P, Heninger GR, Charney DS: The Yale-Brown Obsessive Compulsive Scale II. validity. Arch Gen Psychiatry 46, 1012-1016, 1989.

32. Dunn OJ: Multiple comparison among means. $J$ Am Stat Assoc 56, 52-64, 1961.

33. Berkson J: Limitations of the application of fourfold table analysis to hospital data. Biometrics Bull 2, 47-53, 1946.

34. Christenson GA, MacKenzie TB, Mitchell JE: Adult men and women with trichotillomania. Psychosomatics 35, 142-149, 1994.

35. Greenberg HR, Sarner CA: Trichotillomania: Symptom and syndrome. Arch Gen Psychiatry 12, 482-489, 1965.

36. Muller SA: Trichotillomania: A histopathologic study in sixty-six patients. $J \mathbf{A m}$ Acad Dermatol 23, 56-62, 1990.

37. Friman PC, Rostain A: Trichotillomania (hair pulling). $N$ Engl $J$ Med 332:471, 1990.

38. Friman PC, Blum NH, Rostain A: Is hair pulling benign? J Am Acad Child Adolesc Psychiatry 31, 991-992, 1992.

39. Swedo SE, Rapoport JL: Annotation: Trichotillomania. J Child Psychol Psychiatry 32:401-409, 1991.

40. Kovacs M, Feinberg TL, Crouse-Novak MA, Paulauskas SL, Pollock M, Finkelstein $\mathrm{R}$ : Depressive disorders in childhood: $I$. A longitudinal study of the risk for a subsequent major depression. Arch Gen Psychiatry 41, 643-649, 1984. 